Erratum

\title{
Erratum: Khairul, I.M. et al. Inter-Comparison of Gauge-Corrected Global Satellite Rainfall Estimates and Their Applicability for Effective Water Resource Management in a Transboundary River Basin: The Case of the Meghna River Basin. Remote Sens. $2018,6,828$
}

\author{
Islam M. Khairul ${ }^{1,2, *(1)}$, Nikolaos Mastrantonas ${ }^{3,4}$, Mohamed Rasmy ${ }^{1,2}$, Toshio Koike ${ }^{1,2}$ \\ and Kuniyoshi Takeuchi 5 (iD \\ 1 International Centre for Water Hazard and Risk Management (ICHARM), Public Works Research \\ Institute (PWRI), Tsukuba, Ibaraki 305-8516, Japan; abdul@pwri.go.jp (M.R.); koike@icharm.org (T.K.) \\ 2 National Graduate Institute for Policy Studies (GRIPS), Tokyo 106-8677, Japan \\ 3 Centre for Ecology \& Hydrology, Maclean Building, Wallingford, Oxfordshire OX10 8BB, UK; \\ nikmas@ceh.ac.uk \\ 4 IHE Delft, 2601 DA Delft, The Netherlands \\ 5 University of Yamanashi, Takeda, Kofu, Yamanashi 400-8510, Japan; takeuchi@yamanashi.ac.jp \\ * Correspondence: k-islam55@pwri.go.jp or k196wre@gmail.com; Tel.: +81-29-879-6809
}

After publication of the paper [1], it was found that one of the contributing authors, Nikolaos Mastrantonas, was not included in the original version of the article.

The previous version was incorrect:

Islam M. Khairul ${ }^{1,2, *}$, Mohamed Rasmy ${ }^{1,2}$, Toshio Koike ${ }^{1,2}$ and Kuniyoshi Takeuchi ${ }^{3}$

1 International Centre for Water Hazard and Risk Management (ICHARM), Public Works Research Institute (PWRI), Tsukuba, Ibaraki 305-8516, Japan; abdul@pwri.go.jp (M.R.); koike@icharm.org (T.K.)

2 National Graduate Institute for Policy Studies (GRIPS), Tokyo 106-8677, Japan

3 University of Yamanashi, Takeda, Kofu, Yamanashi 400-8510, Japan; takeuchi@yamanashi.ac.jp

* $\quad$ Correspondence: k-islam55@pwri.go.jp or k196wre@gmail.com; Tel.: +81-29-879-6809

Author Contributions: I.M.K., M.R., T.K., and K.T. conceived and formulated the research; I.M.K. performed all the calculation and assessments; I.M.K. and M.R. analysed the results. M.R., T.K., and K.T provided many suggestive advices. This manuscript was written by I.M.K.

The authorship, affiliations and author contributions section now read:

Islam M. Khairul ${ }^{1,2}$ * , Nikolaos Mastrantonas ${ }^{3,4}$, Mohamed Rasmy ${ }^{1,2}$, Toshio Koike ${ }^{1,2}$ and Kuniyoshi Takeuchi ${ }^{5}$

1 International Centre for Water Hazard and Risk Management (ICHARM), Public Works Research Institute (PWRI), Tsukuba, Ibaraki 305-8516, Japan; abdul@pwri.go.jp (M.R.); koike@icharm.org (T.K.)

2 National Graduate Institute for Policy Studies (GRIPS), Tokyo 106-8677, Japan 
3 Centre for Ecology \& Hydrology, Maclean Building, Wallingford, Oxfordshire, OX10 8BB, UK; nikmas@ceh.ac.uk

4 IHE Delft, 2601 DA, Delft, The Netherlands

5 University of Yamanashi, Takeda, Kofu, Yamanashi 400-8510, Japan; takeuchi@yamanashi.ac.jp

* Correspondence: k-islam55@pwri.go.jp or k196wre@gmail.com; Tel.: +81-29-879-6809

Author Contributions: All authors contributed to the conception and formulation of the research; M.R., T.K., and K.T. supervised the research and provided necessary suggestions. N.M. individually created the particular methodology for merging and quantile mapping bias correction and provided the related computational scripts, literature review, descriptions, and suggestions on their applications. I.M.K. performed all the calculations and produced the results; I.M.K. and M.R. analyzed the results. This manuscript was written by I.M.K and M.R.

The authors would like to apologize for any inconvenience caused. The change does not affect the scientific results. The manuscript will be updated and the original will remain online on the article webpage.

Conflicts of Interest: The authors declare no conflict of interest.

\section{Reference}

1. Khairul, I.M.; Mastrantonas, N.; Rasmy, M.; Koike, T.; Takeuchi, K. Inter-Comparison of Gauge-Corrected Global Satellite Rainfall Estimates and Their Applicability for Effective Water Resource Management in a Transboundary River Basin: The Case of the Meghna River Basin. Remote Sens. 2018, 10, 828. [CrossRef] 